
Multidisciplinary
SCIENTIFIC JOURNAL
OF MARITIME RESEARCH

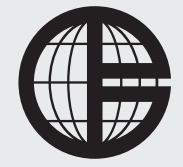
University of Rijeka
FACULTY OF MARITIME STUDIES
Multidisciplinarni
znanstveni časopis
POMORSTVO

\title{
Using Fuzzy AHP Method to Evaluate Key Competency and Capabilities of Selecting Middle Managers for Global Shipping Logistics Service Providers
}

\author{
Ji-Feng Ding ${ }^{1}$, Jung-Fong $\mathrm{Kuo}^{2}$, Wen-Hui Tai ${ }^{3}$ \\ ${ }^{1}$ Department of Aviation and Maritime Transportation Management, Chang Jung Christian University, Tainan City 71101, Taiwan, e-mail: jfding@mail. \\ cjcu.edu.tw \\ ${ }^{2}$ Ph.D. Program in Business and Operations Management, Chang Jung Christian University, Tainan City 71101, Taiwan, e-mail: johnkuo0925@yahoo.com.tw \\ ${ }^{3}$ Department of Tourism Management, Chia Nan University of Pharmacy \& Science, Tainan 71710, Taiwan, e-mail: jessica.taii@msa.hinet.net
}

\section{ABSTRACT}

The main purpose of this article is to use the fuzzy analytic hierarchy process (AHP) method to empirically study the key competency and capabilities affecting the selection of middle managers for global shipping logistics service providers (GSLSPs). To facilitate this theme for obtaining key competency and capabilities, a list of five management competency with twenty-five capabilities are preliminary summarized. Subsequently, the proposed fuzzy AHP method is applied to measure relative weights for evaluating these competency and capabilities. The appraisal approach is then to perform empirical survey via AHP expert questionnaires. Finally, the empirical results show that: (1) 'professional competency' is the most important management competency affecting the selection of middle managers for GSLSPs. (2) In order of relative importance, the top six key management capabilities affecting the selection of middle managers for GSLSPs are the 'capability to manage work pressure,' 'capability to manage crisis,' 'capability to lead team awareness,' 'capability to manage interpersonal networks perfectly,' 'capability to use logistics expertise to enhance work efficiency,' and 'capability to effectively build team spirit and work atmosphere,' respectively. Furthermore, concluding remarks are provided in this article.

\section{ARTICLE INFO}

Original scientific paper

Received 10 December 2018

Accepted 21 January 2019

Key words:

Competency

Capability

Middle managers

Global shipping logistics service provider

Fuzzy AHP method

\section{Introduction}

With the rapid development of international economic activities in recent years, various products of international trade are required to be economical and efficient. The integration of international logistics systems [1] has been considered as a way to strengthen international marketing. In addition, the growth of the regional economy, the evolution of the supply chain concept, the progress of ecommerce, and the deregulation of global finance and transportation [1,2] have also contributed to the vigorous development of international logistics. In other words, with the development trend of international trade, many multinational enterprises have already employed a global layout strategy, hoping to obtain maximum profits through international division of labor, production, and other means. Therefore, the transnational international logistics industry is in urgent demand, showing that international logistics is playing a decisive role in global trade.
The rise and prosperity of global trade have also accelerated the expansion of the global shipping market. Due to fierce competition in the global shipping market, the international logistics services provided by shipping companies have been demonstrated more elaborately in commercial logistics. As a result, the international trade and shipping market has experienced diversified and rapid changes due to fierce competition. Under such a fierce competitive environment, how to provide customers with more comprehensive logistics services will be a very important issue for global shipping logistics service providers (GSLSPs) [1, 3].

The GSLSP has played an important role in third-party logistics providers (3PL). At the same time, it is also a very important logistics auxiliary provider in the international transportation industry [3]. Therefore, in order to provide better shipping logistics services and enhance their own operating performance, enterprises must continue to recruit, train, and retain outstanding talents and then form an efficient work team to develop more effective organi- 
zations [4]. Since the shipping logistics providers need a group of employees who can create organizational business value, on the outside, these personnel must be able to see the market opportunities and maintain a close interaction with the customers, so that they can establish a good external network. On the inside, they must be able to identify and integrate talents with relevant functions in order to grasp market opportunities.

Having excellent manpower is a key factor for a successful enterprise [5]. Enterprise manpower can generally be divided into non-management employees and managers [4]. The former are general employees, while the latter can be divided into first-line managers, middle managers, and top managers. Because they are members of different levels, these managers have different duties and management responsibilities with each one performing his/her own functions. In the above three types of managers, middle managers often play the role of a connecting link. In the distribution of work or the communication and execution of policies, middle managers act as important information transmitters between the operation department and the decision-making department in organizations [4, 6-8]. Therefore, the selection of a middle manager with management competency and capabilities [9] will have a decisive influence on the development of the organization.

Management competency is an ability that managers of the organization must have to perform their duties in order to effectively achieve the objectives or performance set by them $[4,6,7]$. Because the evaluation of management competency and the capabilities of middle managers involve many assessment aspects and criteria, the research scope and level they cover is extensive and complex. The Analytic Hierarchy Process (AHP) [10] is a set of decisionmaking methods that systematizes complex problems. It is mainly applied to uncertain situations and multi-attribute decision-making problems and belongs to the research field of multi-criteria decision-making (MCDM). Therefore, this study evaluates the relative importance of the management competency and capabilities of middle managers through the AHP method. In addition, indicators of management competency and capabilities have qualitative characteristics, and there is ambiguity in evaluators' subjective assertion of the problem. Therefore, it is difficult to express the importance of key competency and key capabilities with accurate numerical values. This study uses the fuzzy set theory [11] with the cooperation of the AHP method to construct the fuzzy AHP evaluation model [12-14] and then employs it as the main mode for GSLSP to evaluate the key competency and capabilities of middle managers. In light of this, the main purpose of this paper is to use the fuzzy AHP method to empirically study the key competency and capabilities affecting the selection of middle managers for GSLSPs. The first section provides background information concerning this issue, the following section describes the fuzzy AHP method, the third section consists of an empirical study, and the final section presents conclusions.

\section{Research method}

The fuzzy AHP method used in this paper is briefly introduced in this section.

\subsection{The Concept of Fuzzy Numbers}

In a universe of discourse $X$, a fuzzy subset $\tilde{A}$ of $X$ is defined by a membership function $f_{\hat{A}}(x)$, which maps each element $x$ in $X$ to a real number in the interval $[0,1]$. The value of function $f_{\hat{A}}(x)$ represents the grade of membership of $x$ in $\tilde{A}$.

A fuzzy number $\tilde{A}[15]$ in real line $\mathcal{R}$ is a triangular fuzzy number if its membership function $f_{\tilde{A}}: \mathcal{R} \rightarrow[0,1]$ is

$$
f_{\tilde{A}}(x)= \begin{cases}(x-c) /(a-c), & c \leq x \leq a \\ (x-b) /(a-b), & a \leq x \leq b \\ 0, & \text { otherwise }\end{cases}
$$

with $-\infty<c \leq a \leq b<\infty$. A triangular fuzzy number can be denoted by $(c, a, b)$.

In this article, Zadeh's extension principle [11] is employed to perform algebraic operations involving fuzzy numbers. Let $\tilde{A}_{1}=\left(c_{1}, a_{1}, b_{1}\right)$ and $\tilde{A}_{2}=\left(c_{2}, a_{2}, b_{2}\right)$ be fuzzy numbers. The algebraic operations of any two fuzzy numbers $\tilde{A}_{1}$ and $\tilde{A}_{2}$ can be expressed as:

(1) Fuzzy addition, $\oplus$ :

$$
\tilde{A_{1}} \oplus \tilde{A}_{2}=\left(c_{1}+c_{2}, a_{1}+a_{2}, b_{1}+b_{2}\right) ;
$$

(2) Fuzzy subtraction, $\ominus$ :

$$
\tilde{A}_{1} \ominus \tilde{A}_{2}=\left(c_{1}-b_{2}, a_{1}-a_{2}, b_{1}-c_{2}\right)
$$

(3) Fuzzy multiplication, $\otimes:$

$$
\begin{aligned}
& k \otimes \tilde{A}_{2}=\left(k c_{2}, k a_{2}, k b_{2}\right) ; k \in \mathcal{R}, \mathrm{k} \geq 0 ; \\
& \tilde{A}_{1} \otimes \tilde{A}_{2} \cong\left(c_{1} c_{2}, a_{1} a_{2}, b_{1} b_{2}\right) ; c_{1} \geq 0, c_{2} \geq 0 .
\end{aligned}
$$

(4) Fuzzy division, $\varnothing$ :

$$
\begin{aligned}
& \left(\tilde{A}_{1}\right)^{-1}=\left(c_{1}, a_{1}, b_{1}\right)^{-1} \cong\left(1 / b_{1}, 1 / a_{1}, 1 / c_{1}\right) ; c_{1}>0 ; \\
& \tilde{A}_{1} \varnothing \tilde{A}_{2} \cong\left(c_{1} / b_{2}, a_{1} / a_{2}, b_{1} / c_{2}\right) ; c_{1} \geq 0, c_{2} \geq 0 .
\end{aligned}
$$

\subsection{The Fuzzy AHP Method}

In the field of MCDM problems, there are many academic literatures using the fuzzy AHP method $[1,2,3,8$, 9]. Two methods - proposed by Buckley [12] and Chang [16] - are usually used in the academic literature. Buckley [12] extended a hierarchical analysis using a consistency test method for fuzzy positive reciprocal matrices in which all elements are trapezoidal fuzzy numbers. Buckley et al. [17] revisited the fuzzy hierarchical analysis and proposed a new method of finding the fuzzy weights. Chang [16] employed the same procedure in building fuzzy pair-wise comparison matrices. However, two important steps of Chang's extent analysis method on fuzzy AHP are added to calculate 
the value of the fuzzy synthetic extent and the degree of possibility of any two fuzzy numbers. Chang's method [16] was then modified by Ding [13]. After that, Ding [13] applied the proposed method to evaluate a suitable partner of strategic alliance for a liner shipping company. In this paper, the fuzzy AHP procedure of Ding et al. method [14] is used to evaluate relative weights. The steps are described below.

\section{Step 1 Establishing a Hierarchical Structure}

This step employs the hierarchical framework diagram shown in Figure 1. In this framework, the research problems (goal) lie on the $L$ layer. There are $k$ assessment aspects (management competency) on the $L+1$ layer, and $p+---+q+---+r$ evaluation criteria (management capabilities) on the $L+2$ layer.

Because professional middle managers have the special status in enterprise organizations [8], some management competency and capabilities for middle managers are increasingly valued by human resources scholars [4-7]. In terms of successful innovation schemes, the motivation of new ideas, and the execution of new strategic directions inside the enterprise [18], the role of the connecting link played by middle managers has made important contributions to enterprises [8]. After top managers make plans for an enterprise's future direction and related important issues, they must be given to middle and first-line managers as well as non-management employees for execution [8]. At this time, first-line managers and non-management employees often play important roles in execution operations $[4,6,7]$. However, when top managers and first-line managers have different perceptions of the objectives of the organization, there must be someone to effectively transmit enterprise objectives between top managers and first-line managers. It is necessary to rely on the management competency and management capabilities of middle managers $[9,19-21]$ to effectively link top managers, first-line managers, and non-management employees to jointly execute common performance objectives of the enterprise $[1,5]$.

Hence, this study cites the relevant academic literature $[1,3-9,18-21]$ and then interview experts and scholars as well as heads of human resources department in GSLSP. Finally, this study obtains the assessment aspects and evaluation criteria for measuring the middle managers, including 5 management competencies and 20 management capabilities. Their codes are shown in parentheses, as described below.

Leadership Competency $\left(C_{1}\right)$. This assessment aspect includes 4 evaluation criteria: the 'capability to effectively build team spirit and work atmosphere $\left(C_{11}\right)$,' the 'capability to positively motivate subordinates $\left(C_{12}\right)$,' the 'capability to influence subordinates to support the team $\left(C_{13}\right)$,' and the 'capability to impartially and objectively evaluate the performance of subordinates $\left(C_{14}\right)$.'

Interpersonal Competency $\left(C_{2}\right)$. This assessment aspect includes 4 evaluation criteria: the 'capability to integrate and coordinate $\left(C_{21}\right)$,' the 'capability to lead team awareness $\left(C_{22}\right)$,' the 'capability to communicate in spoken language $\left(C_{23}\right)$,' and the 'capability to manage interpersonal networks perfectly $\left(C_{24}\right)$.'

Administrative Competency $\left(C_{3}\right)$. This assessment aspect includes 4 evaluation criteria: the 'capability to effectively interpret relevant administrative information $\left(C_{31}\right)$,' the 'capability to manage crisis $\left(C_{32}\right)$,' the 'capability to transform conceptual schemes into executable strategic plans $\left(C_{33}\right)$,' and the 'capability to effectively manage and allocate available resources $\left(C_{34}\right)$ '.

Professional Competency $\left(C_{4}\right)$. This assessment aspect includes 4 evaluation criteria: the 'capability to thoroughly understand the work procedures of logistics and related practices $\left(C_{41}\right)$,' the 'capability to manage work pressure $\left(C_{42}\right)$,' the 'capability to use logistics expertise to enhance work efficiency $\left(C_{43}\right)$,' and the 'capability to have cross-divisional work experience $\left(C_{44}\right)$ '.

Conceptual Competency $\left(C_{5}\right)$. This assessment aspect includes 4 evaluation criteria: the 'capability to simplify complex issues $\left(C_{51}\right)$,' the 'capability to integrate resources within and outside related organizations $\left(C_{52}\right)$,' the 'capability to plan and organize $\left(C_{53}\right)$,' and the 'capability to properly understand the internal and external competitive environment $\left(C_{54}\right)$ '

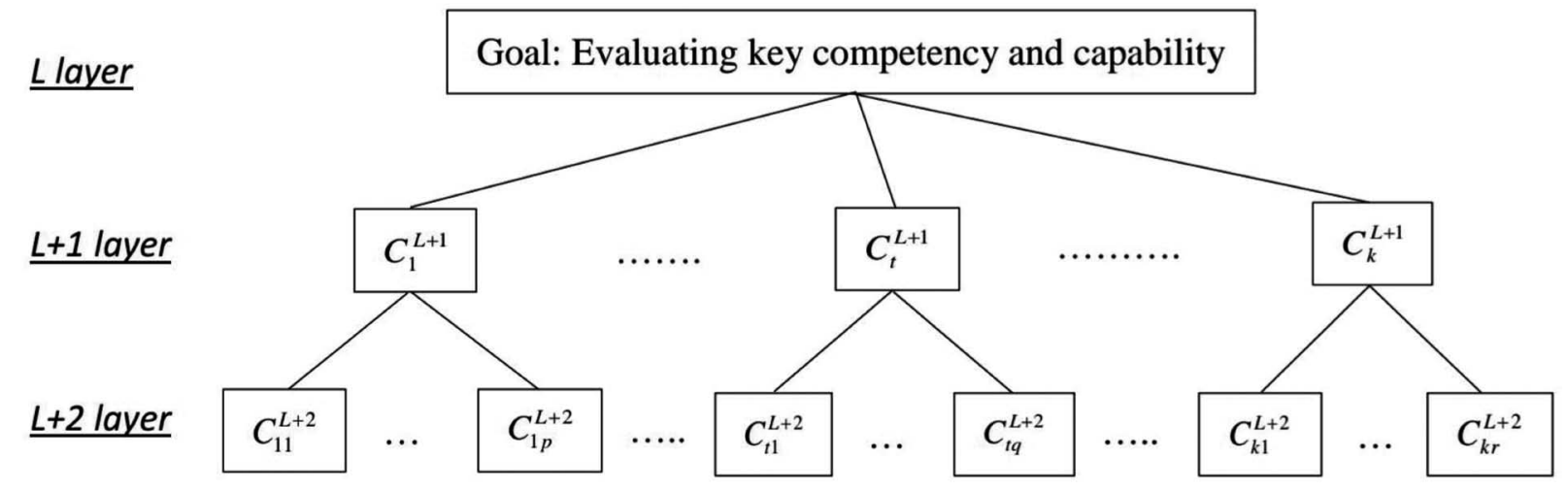

Figure 1 Hierarchical structure Source: [14] 


\section{Step 2 Establishing Pair-wise Comparison Matrices for Decision Attributes}

Pair-wise comparison of AHP questionnaire results has been employed to determine the experts' views of the relative importance of paired assessment criteria [10, 12, $14,17]$.

Let $x_{i j}^{h}, h=1,2, \ldots, n$, be the relative importance assigned to any two assessment aspects $i$ and $j$ by expert $h$ on the $L+1$ layer. Then, the pair-wise comparison matrix is defined as $\left[x_{i j}^{h}\right]_{k \times k}$ *

Let $x_{u v^{\prime}}^{h} h=1,2, \ldots, n$, be the relative importance assigned to any two evaluation criteria $u$ and $v$ by expert $h$ on the $L+2$ layer. Then, the pair-wise comparison matrix with respect to each assessment aspect, i.e. $C_{1}^{L+1}, C_{t}^{L+1}, C_{k}^{L+1}$, is defined as $\left[x_{u v}^{h}\right]_{p \times p^{\prime}}\left[x_{u v}^{h}\right]_{q \times q^{\prime}}\left[x_{u v}^{h}\right]_{r \times r^{*}}$

\section{Step 3 Establishing Triangular Fuzzy Numbers}

To aggregate all information generated by different averaging operations [22], we have used the grade of membership to demonstrate their strength after considering all approaches. Triangular fuzzy numbers characterized through use of min, max and geometric mean operations [10, 23] have therefore been used to convey the views of all experts.

Let $x_{i j}^{h} \in[1 / 9,1 / 8, \ldots, 1 / 2,1] \cup[1,2, \ldots, 8,9], h=1,2, \ldots$, $n, \forall i, j=1,2, \ldots, k$, be the relative importance assigned to any two assessment aspects $i$ and $j$ by expert $h$ on the $L+1$ layer. After integrating the views of all $n$ experts, the triangular fuzzy numbers can be expressed as

$$
\tilde{A}_{i j}^{L+1}=\left(c_{i j}, a_{i j}, b_{i j}\right) \text {, }
$$

where $c_{i j}=\min \left\{x_{i j^{\prime}}^{1}, x_{i j^{\prime}}^{2}, \ldots, x_{i j}^{n}\right\}, a_{i j}=\left(\prod_{h=1}^{n} x_{i j}^{h}\right)^{1 / n}, b_{i j}=\max \left\{x_{i j^{\prime}}^{1}\right.$
$\left.x_{i j}^{2}, \ldots, X_{i j}^{n}\right\}$.

We can integrate the views of all $n$ experts on the $L+2$ layer in the same way, so that the triangular fuzzy numbers can be expressed as

$$
\begin{aligned}
& \tilde{A}_{u v}^{L+2}=\left(c_{u v}, a_{u v}, b_{u v}\right), \forall u, v=1, \ldots, p ;---; \\
& \forall u, v=1, \ldots, q ;--; \forall u, v=1, \ldots, r
\end{aligned}
$$

where $c_{u v}=\min \left\{x_{u v}^{1}, x_{u v}^{2}, \ldots, x_{u v}^{n}\right\}, a_{u v}=\left(\prod_{h=1}^{n} x_{u v}^{h}\right)^{1 / n}, b_{u v}=\max$
$\left\{x_{u v}^{1}, x_{u v}^{2}, \ldots, x_{u v}^{n}\right\}$.

\section{Step 4 Constructing Fuzzy Positive Reciprocal Matrices}

We have used the integrated triangular fuzzy numbers to construct fuzzy positive reciprocal matrices [14]. For the $L+1$ layer, the fuzzy positive reciprocal matrix can be expressed as

$$
A=\left[\widetilde{A}_{i j}^{L+1}\right]=\left[\begin{array}{cccc}
1 & \widetilde{A}_{12}^{L+1} & \cdots & \widetilde{A}_{1 k}^{L+1} \\
1 / \widetilde{A}_{12}^{L+1} & 1 & \cdots & \widetilde{A}_{2 k}^{L+1} \\
\vdots & \vdots & \ddots & \vdots \\
1 / \widetilde{A}_{1 k}^{L+1} & 1 / \widetilde{A}_{2 k}^{L+1} & \cdots & 1
\end{array}\right]
$$

where $\tilde{A}_{i j}^{L+1} \otimes \tilde{A}_{j i}^{L+1} \cong 1, \forall i, j=1,2, \ldots, k$.
The equations of the fuzzy positive reciprocal matrices on the $L+2$ layer can be obtained using an analogous method.

\section{Step 5 Calculating the Fuzzy Weights of the Fuzzy Positive Reciprocal Matrices}

Let $\tilde{Z}_{i}^{L+1} \cong\left(\tilde{A}_{i 1}^{L+1} \otimes \tilde{A}_{i 2}^{L+1} \otimes---\otimes \tilde{A}_{i k}^{L+1}\right)^{1 / k}, \forall i=1,2, \ldots, k$, be the geometric mean of triangular fuzzy number $[10,14$, 22 ] of the $i^{\text {th }}$ assessment aspect on the $L+1$ layer. The fuzzy weight of the $i^{\text {th }}$ assessment aspect can then be expressed as

$$
\tilde{W}_{i}^{L+1} \cong \tilde{Z}_{i}^{L+1} \otimes\left(\tilde{Z}_{1}^{L+1} \oplus \tilde{Z}_{2}^{L+1} \oplus---\oplus \tilde{Z}_{k}^{L+1}\right)^{-1}
$$

For convenience, the fuzzy weight is expressed as $\tilde{W}_{i}^{L+1}=\left(w_{i c}, w_{i a}, w_{i b}\right)$. The equations of fuzzy weights on the $L+2$ layer can be obtained using an analogous method.

\section{Step 6 Defuzzifying the Fuzzy Weights to obtain Crisp Weights}

To perform defuzzification in an effective manner, the graded mean integration representation (GMIR) method proposed by Chen and Hsieh [24] has been used to defuzzify the fuzzy weights.

Let $\tilde{W}_{i}^{L+1}=\left(w_{i c}, w_{i a}, w_{i b}\right), \forall i=1,2, \ldots, k$, be $k$ triangular fuzzy numbers. The GMIR of crisp weights $k$ can then be expressed as

$$
W_{i}^{L+1}=\frac{w_{i c}+4 w_{i a}+w_{i b}}{6}, \forall i, j=1,2, \ldots, k .
$$

The defuzzification of fuzzy weights on the $L+2$ layer can be performed using an analogous method.

\section{Step 7 Normalizing the Crisp Weights}

To facilitate comparison of the relative importance of assessment aspects on different layers, the crisp weights have been normalized $[13,14]$ and expressed as

$$
N W_{i}^{L+1}=\frac{W_{i}^{L+1}}{\sum_{i=1}^{k} W_{i}^{L+1}}
$$

\section{Step 8 Calculating the Integrated Weights for Each Layer}

Let $N W_{i}^{L+1}$ and $N W_{u}^{L+2}$ be the normalized crisp weights $[13,14]$ on the $L+1$ and $L+2$ layers. Then, the integrated weight of each assessment aspect (management competency) on the $L+1$ layer is

$$
I W_{u}^{L+1}=N W_{i}^{L+1}, \forall i=1,2, \ldots, k .
$$

The integrated weight of each evaluation criterion (management capability) on the $L+2$ layer is

$$
\begin{aligned}
& I W_{u}^{L+2}=N W_{i}^{L+1} \times N W_{u}^{L+2}, \\
& \forall i=1,2, \ldots, k ; \forall u=1, \ldots, p ;---; \forall u=1, \ldots, q,---; \\
& \forall u=1, \ldots, r .
\end{aligned}
$$




\section{Empirical study}

This section describes an empirical study conducted to evaluate key competency and capabilities affecting the selection of middle managers for GSLSPs in Taiwan.

\subsection{Data collection}

The AHP expert questionnaire has been based on the 5 assessment aspects (competency) and 20 evaluation criteria (capabilities) shown in Step 1 of the fuzzy AHP method (Section 2.2), and has been applied to investigate the relative weights of all management capabilities. To check whether the expressions have been clear or important questions have been missed, 3 managers and 2 scholars have been invited to pre-test the questionnaire. Finally, two rounds of correction based on questionnaire design principles have been carefully performed, and the final AHP questionnaire has been completed.

The AHP questionnaires were distributed during a two-month period in 2018. The top managers working at GSLSPs in Taiwan were invited to fill in the AHP questionnaires. The surveys were completed through e-mails, phone calls, and in-person interviews conducted by the authors. The returned questionnaires were checked to determine whether the consistency index (C.I.) of each matrix of every layer was lower than 0.1 [10]. When the C.I. value of a matrix is higher than 0.1 , this implies that the respondent have made an inconsistent pair-wise comparison of two management competency (or management capabilities). By the way, the judgment and verification of the pair-wise comparison matrix is a very important issue [10]. If there is a pair-wise comparison matrix that does not conform to the consistency, it shows that the expert's judgment is confusing. At this time, the expert must re-evaluate the pair-wise comparison matrix until the consistency requirement is met. Because the AHP expert questionnaire process is cumbersome, in the practical ap- plication, direct access by personnel is better, and the consistency of expert judgment on the spot is verified, so that each questionnaire can become an effective questionnaire.

A total of 30 questionnaires were issued, of which 26 valid questionnaires were recovered, for an effective recovery rate of $86.67 \%$. In view of Robinson's recommendation [25] that 5-7 experts ideally be enlisted in research on group decision-making problems, the 26 valid recovered questionnaires should be sufficient to provide a representative range of views. As a result, after the 26 questionnaires were checked for validity, the number of responses was deemed acceptable.

\subsection{Results}

In this case, there are six $(1+5)$ pair-wise comparison matrices to collect. In this section, the authors have used the five management competency (i.e., $C_{1}-C_{5}$ on the $L+1$ layer shown in Figure 1) of valid questionnaires as an example for illustrating the computational process of the fuzzy AHP method. As regards to the other five pair-wise comparison matrices, these have been omitted by reasoning by analogy. And, then calculate the integrated weights for each layer. Finally, the computing process and empirical results are shown as follows.

\section{Step 1 Building Fuzzy Positive Reciprocal Matrix}

The authors have used the data of relative importance of 26 valid questionnaires to collect fuzzy pair-wise comparison matrices and then have transformed these data into fuzzy positive reciprocal matrix using geometric mean approach. Table 1 shows the results obtained.

\section{Step 2 Calculating the Fuzzy Weights of Fuzzy Positive Reciprocal Matrix}

Using the Step 5 of the fuzzy AHP method, the geometric mean of triangular fuzzy number $\left(\tilde{Z}_{i}^{L+1}\right)$ and the fuzzy weights $\left(\tilde{W}_{i}^{L+1}\right)$ of five assessment aspects can be seen in Table 2 .

Table 1 The fuzzy positive reciprocal matrix of five assessment competency

\begin{tabular}{|c|c|c|c|c|c|}
\hline & $C_{1}$ & $C_{2}$ & $C_{3}$ & $C_{4}$ & $C_{5}$ \\
\hline$C_{1}$ & $(1,1,1)$ & $(0.17,0.73,5)$ & $(0.20,0.85,7)$ & $(0.13,0.53,7)$ & $(0.50,1.74,6)$ \\
\hline$C_{2}$ & $(0.20,1.50,6)$ & $(1,1,1)$ & $(0.25,2.03,5)$ & $(0.14,0.98,8)$ & $(0.20,2.55,9)$ \\
\hline$C_{3}$ & $(0.14,1.18,5)$ & $(0.20,0.49,4)$ & $(1,1,1)$ & $(0.11,0.64,5)$ & $(0.14,1.48,5)$ \\
\hline$C_{4}$ & $(0.14,1.90,8)$ & $(0.13,1.02,7)$ & $(0.20,1.57,9)$ & $(1,1,1)$ & $(0.25,3.16,8)$ \\
\hline$C_{5}$ & $(0.17,0.58,2)$ & $(0.11,0.39,5)$ & $(0.20,0.68,7)$ & $(0.13,0.32,4)$ & $(1,1,1)$ \\
\hline
\end{tabular}

Note: Nomenclature of $C_{1}, C_{2}, \ldots, C_{5}$ can be referred to Step 1 of Section 2.2. Source: The authors.

Table 2 The geometric mean of triangular fuzzy number and the fuzzy weights

\begin{tabular}{|c|c|c|}
\hline & $\tilde{Z}_{i}^{L+1}$ & $\tilde{W}_{i}^{L+1}$ \\
\hline$i=1$ & $(0.294,0.894,4.230)$ & $(0.014,0.166,3.470)$ \\
\hline$i=2$ & $(0.269,1.501,4.644)$ & $(0.013,0.278,3.747)$ \\
\hline$i=3$ & $(0.212,0.887,3.466)$ & $(0.010,0.164,2.797)$ \\
\hline$i=4$ & $(0.246,1.572,5.261)$ & $(0.012,0.291,4.246)$ \\
\hline$i=5$ & $(0.217,0.548,3.086)$ & $(0.010,0.101,2.490)$ \\
\hline
\end{tabular}

Source: The authors. 


\section{Step 3 Defuzzifying the Fuzzy Weights and Standarize the Crisp Weights}

Using the Step 6 of the fuzzy AHP method, the fuzzy weights can be defuzzified by the GMIR method to obtain the crisp weights $\left(W_{i}^{L+1}\right)$. Then using the Step 7, we can obtain the standardized weights $\left(I W_{i}^{L+1}\right)$. The results are shown in Table 3.

\section{Step 4 Calculating the Integrated Weights}

For saving space, the authors have used the same computational process of the fuzzy AHP method for each layer to obtain the standardized weights. And then, the results of the integrated weights are shown in Table 4.

The findings of the AHP survey have been as follows:

(1) 'Professional competency' is ranked highest, indicating that it is the most important assessment aspect affecting the selection of middle managers for GSLSPs based on the Taiwanese perspective. 'Interpersonal competency,' 'leadership competency,' and 'administrative competency' are ranked in the second, third and fourth places. 'Conceptual competency' is the lowest weight rank.
(2) For the 'leadership competency' aspect by the normalized weights, the 'capability to effectively build team spirit and work atmosphere' is the critical evaluation criterion. For the 'interpersonal competency' aspect, the 'capability to lead team awareness' is the critical evaluation criterion. For the 'administrative competency' aspect, the 'capability to manage crisis' is the critical evaluation criterion. For the 'professional competency' aspect, the 'capability to manage work pressure' is the critical evaluation criterion. For the 'conceptual competency' aspect, the 'capability to integrate resources within and outside related organizations' is the critical evaluation criterion.

(3) Daniel [26] feels that most industries possess from two to six key elements that determine success, and a company that wishes to be successful must apply particular effort to these elements. As a consequence, the empirical results show that the top six key capabilities influencing middle managers selection for GSLSPs are the 'capability to manage work pressure,' 'capability to manage crisis,' 'capability to lead team awareness,' 'capability to manage interpersonal networks perfectly,' 'capability to use logistics expertise to enhance work

Table 3 The defuzzified and standardized weights of five assessment aspects

\begin{tabular}{|l|c|c|c|c|c|}
\hline & $C_{1}$ & $C_{2}$ & $C_{3}$ & $C_{4}$ & $C_{5}$ \\
\hline Defuzzified weights & 0.6910 & 0.8119 & 0.5772 & 0.9037 & 0.4844 \\
\hline Standardized weights & 0.1992 & 0.2341 & 0.1664 & 0.2606 & 0.1397 \\
\hline
\end{tabular}

Note: Nomenclature of $C_{1}, C_{2}, \ldots, C_{5}$ can be referred to Step 1 of Section 2.2. Source: The authors.

Table 4 The normalized and integrated weights of each layer

\begin{tabular}{|c|c|c|c|c|}
\hline Competency & Normalized/ Integrated weights (A) & Capability & Normalized weights (B) & $\begin{array}{l}\text { Integrated weights } \\
(\mathrm{C})=(\mathrm{A})^{*}(\mathrm{~B})\end{array}$ \\
\hline \multirow{4}{*}{$C_{1}$} & \multirow{4}{*}{$0.1992(3)$} & $C_{11}$ & $0.3146(1)$ & $0.0627(6)$ \\
\hline & & $C_{12}$ & $0.2437(3)$ & $0.0486(10)$ \\
\hline & & $C_{14}$ & $0.1803(4)$ & $0.0359(16)$ \\
\hline & & $C_{13}$ & $0.2614(2)$ & $0.0521(8)$ \\
\hline \multirow{3}{*}{$C_{2}$} & \multirow{3}{*}{$0.2341(2)$} & $C_{21}$ & $0.2097(3)$ & $0.0491(9)$ \\
\hline & & $C_{23}$ & $0.1713(4)$ & $0.0401(13)$ \\
\hline & & $C_{24}$ & $0.3066(2)$ & $0.0718(4)$ \\
\hline \multirow{3}{*}{$C_{3}$} & \multirow{3}{*}{$0.1664(4)$} & $C_{31}$ & $0.1104(4)$ & $0.0184(20)$ \\
\hline & & $C_{32}$ & $0.4546(1)$ & $0.0756(2)$ \\
\hline & & $C_{33}$ & $0.2382(2)$ & $0.0396(14)$ \\
\hline \multirow{2}{*}{$C_{4}$} & \multirow{2}{*}{$0.2606(1)$} & $C_{43}$ & $0.2418(2)$ & $0.0630(5)$ \\
\hline & & $C_{44}$ & $0.2212(3)$ & $0.0576(7)$ \\
\hline \multirow{4}{*}{$C_{5}$} & \multirow{4}{*}{$0.1397(5)$} & $C_{51}$ & $0.1724(4)$ & $0.0241(19)$ \\
\hline & & $C_{52}$ & $0.3177(1)$ & $0.0444(12)$ \\
\hline & & $C_{53}$ & $0.2416(3)$ & $0.0338(17)$ \\
\hline & & $C_{54}$ & $0.2683(2)$ & $0.0375(15)$ \\
\hline
\end{tabular}

Notes: (1) Nomenclature of $C_{1}, \ldots, C_{5}$, and $C_{11}, C_{21}, \ldots, C_{54}$ can be referred to Step 1 of Section 2.2. (2) Numbers in parentheses are ranks. Source: The authors. 
efficiency,' and 'capability to effectively build team spirit and work atmosphere,' respectively.

From the above research results, it can be seen that among the elements of selecting middle managers, two key capabilities have been located in "professional competence" aspect, two key capabilities have been located in "interpersonal competency" aspect, one key capability has been located in "administrative competence" aspect, and one key capability has been located in "leadership competency" aspect. In particular, when middle managers face managers of upper and lower levels, how do they confront work pressure and use related professional knowledge to enhance work efficiency? How do they lead the team and create a working atmosphere? How do they run the network of human relationships? How do they deal with a crisis when it occurs? Therefore, if GSLSP can build key capabilities suitable for middle managers, then it is believed that the human resource management (HRM) department will be better able to hire and select outstanding talents. In addition, for employees within the enterprise, these standards or conditions can be followed by those with ambitions and can be used to improve their self-ability, which is conducive to obtaining the qualification for the promotion within the enterprise in the future.

\section{Concluding remarks}

GSLSP has played an important role in the global shipping market, because GSLSP can provide professional and all-around comprehensive solutions for the shipping service [27]. In order to help provide better shipping logistics services, excellent logistics talents are an important factor in leading enterprises to upgrade and enhance customer satisfaction. Therefore, recruiting management talents with excellent competency and capabilities is an important direction for HRM departments. In addition, middle managers often play the role of a connecting link and act as important information transmitters between the operation department and the decision-making department in organizations. Based on this, the selection of a middle manager with management competency and capabilities will have a decisive influence on the development of the organization.

The main research purpose of this paper is to evaluate the key competency and capabilities to select middle managers for GSLSP. It mainly uses the fuzzy AHP model and the AHP expert questionnaire to select the important key competencies and capabilities that middle-level managers should possess. The empirical results of the study have mainly shown the following. First of all, "professional competency" is the primary key competency to select middle managers, and the most important management capability to represent "professional competency" is the "capability to manage work pressure." Subsequently, the top six key capabilities influencing middle managers selection for GSLSPs are the 'capability to manage work pressure,' 'capability to manage crisis,' 'capability to lead team awareness,' 'capability to manage interpersonal networks perfectly,' 'capability to use logistics expertise to enhance work efficiency,' and 'capability to effectively build team spirit and work atmosphere,' respectively. Finally, two key capabilities have been located in "professional competence," two key capabilities in "interpersonal competency," one key capability in "administrative competence," and one key capability in "leadership competency."

This study has suggested that, in the future, when selecting middle managers, GSLSP may be particularly focused on the management competency and management capabilities acquired in this study in order for better middle-level talents to be selected. In addition, this paper with its proposed method can be employed as a practical tool for GSLSP business applications. A layer of alternatives can also be added to Figure 1 as a complete hierarchy in the future research, so that we can compare the decision value to assess the attractiveness of alternatives. The results of the study presented in this paper can serve as a reference to select middle managers for the HRM department of GSLSP. Furthermore, the common fuzzy AHP method has been used to solve the subjective nature in this paper. However, in many cases, it is often difficult or impossible to obtain the exact membership function of the multiplication and division algebraic operations results of any two or more than two triangular fuzzy numbers [28]. In the future study, we suggest the $\alpha$-cut [28] based method on fuzzy AHP to avoid controversies that may arise due to different approaches and attitudes of decision-makers.

\section{References}

[1] Prajogo, D., Oke, A. and Olhager, J. (2016). Supply chain processes: Linking supply logistics integration, supply performance, lean processes and competitive performance. International Journal of Operations and Production Management, 36(2), pp. 220-238.

[2] Notteboom, T. and Rodrigue, J. (2008). Containerisation, box logistics and global supply chains: The integration of ports and liner shipping networks. Maritime Economics and Logistics, 10(1-2), pp. 152-174.

[3] Rodrigue, J. (2012). The geography of global supply chains: Evidence from third-party logistics. Journal of Supply Chain Management, 48(3), pp. 15-23.

[4] Jones, G. R. and George, J. M. (2016). Essentials of Contemporary Management ( $7^{\text {th }}$ ed.). McGraw-Hill, New York.

[5] Kiessling, T. and Harvey, M. (2014). Human resource management issues associated with the globalization of supply chain management and logistics. International Journal of Physical Distribution \& Logistics Management, 44(8/9), https://doi.org/10.1108/IJPDLM-05-2014-0115.

[6] DuBrin, A. J. (2016). Essential of Management (10 ${ }^{\text {th }}$ ed.). Thomson South-Western, Singapore.

[7] Robbins, S. P., Coulter, M. and DeCenzo, D. A. (2016). Fundamentals of Management: Essential Concepts and Applications $\left(10^{\text {th }}\right.$ ed.). Pearson Education, Singapore.

[8] Tinline, G. and Cooper, C. (2016). The Outstanding Middle Manager. Kogan Page Limited, London.

[9] Fang, C. H., Chang, S. T. and Chen, G. L. (2010). Competency development among Taiwanese healthcare middle manager: 
A test of the AHP approach. African Journal of Business Management, 4(13), pp. 2845-2855.

[10] Saaty, T. L. (1980). The Analytic Hierarchy Process. McGrawHill Companies, New York.

[11] Zadeh, L. A. (1965). Fuzzy sets. Information and Control, 8(3), pp. 338-353.

[12] Buckley, J. J. (1985). Fuzzy hierarchical analysis. Fuzzy Sets and Systems, 17(3), pp. 233-247.

[13] Ding, J. F. (2009). Partner selection of strategic alliance for a liner shipping company using extent analysis method of fuzzy AHP. Journal of Marine Science and Technology, 17(2), pp. 97-105.

[14] Ding, J. F., Dye, C. Y., Liang, S. Y., Chou, C. C., Tseng, W. J. and Shyu, W. H. (2017). Evaluating key factors influencing the development of multi-country consolidation for ocean freight forwarders in Taiwan. Proceedings of the Institution of Mechanical Engineers Part M: Journal of Engineering for the Maritime Environment, 231(1), pp. 342-352.

[15] Dubois, D., Prade, H. (1978). Operations on fuzzy numbers. The International Journal of Systems Science, 9(6), pp. 613626.

[16] Chang, D. Y. (1996). Application of the extent analysis method on fuzzy AHP. European Journal of Operational Research, 95(3), pp. 649-655.

[17] Buckley, J. J., Feuring, T. and Hayashi, Y. (2001). Fuzzy hierarchical analysis revisited. European Journal of Operational Research, 129(1), pp. 48-64.

[18] Fisher, E. (2011). What practitioners consider to be the skills and behaviours of an effective people project manager. International Journal of Project Management, 29(8), pp. 994-1002.
[19] Chen, P., Partington, D. and Wang, J. N. (2008). Conceptual determinants of construction project management competence: A Chinese perspective. International Journal of Project Management, 26(6), pp. 655-664.

[20] Crawford, L. and Nahmias, A. H. (2010). Competencies for managing change. International Journal of Project Management, 28(4), pp. 405-412.

[21] Kotzab, H., Teller, C., Bourlakis, M. and Wünsche, S. (2018). Key competences of logistics and SCM professionals - The lifelong learning perspective. Supply Chain Management: An International Journal, 23(1), pp. 50-64.

[22] Klir, G. L. and Yuan, B. (1995). Fuzzy Sets and Fuzzy Logic: Theory and Application. Prentice-Hall, New York.

[23] Hsu, T. H. (1998). The fuzzy analytic hierarchy process. Journal of the Chinese Fuzzy Systems, 4(1), pp. 59-72.

[24] Chen, S. H. and Hsieh, C. H. (2000). Representation, ranking, distance, and similarity of L-R type fuzzy number and application. Australian Journal of Intelligent Information Processing Systems, 6(4), pp. 217-229.

[25] Robbins, S. P. (1994). Management, Prentice-Hall, New Jersey.

[26] Daniel, R. D. (1961). Management information crisis. Harvard Business Review, 39(5), pp. 111-121.

[27] Shin, Y., Thai, V. V., Grewal, D. and Kim, Y. (2017). Do corporate sustainable management activities improve customer satisfaction, word of mouth intention and repurchase intention? Empirical evidence from the shipping industry. The International Journal of Logistics Management, 28(2), pp. 555-570.

[28] Liang, G. S. and Ding, J. F. (2003). Fuzzy MCDM based on the concept of $\alpha$-cut. Journal of Multi-Criteria Decision Analysis, 12(6), pp. 299-310. 